The International Journal of Engineering and Science (IJES)

|| Volume || 6 || Issue || 3 || Pages || PP 55-57 || 2017 ||

ISSN (e): $2319-1813$ ISSN (p): $2319-1805$

\title{
Intelligent Travelling System
}

\author{
Sarassri.S ${ }^{1}$, R.Pavithra ${ }^{2}$, V.Jananee ${ }^{3}$ \\ Assistant Professor ${ }^{1}$, Department Of Computer Science and Engineering, Rajalakshmi Engineering College, \\ Thandalam, Chennai
}

In artificial intelligence, an expert system is the computer system that emulates the decision making ability of a human expert. Expert systems are designed to solve the complex problems by reasoning about the knowledge represented primarily as If-then rules rather than through conventional procedural code Intelligent Travelling System is the system that will run on most of the phones and palms which enable the user to visit the places at user criteria. In the current situations, systems have the information about the places they want to visit and they don't have usable or valuable information about points of interest except the phone numbers and addresses. In order to overcome this problem the Intelligent Travelling System has been proposed. The users who want to travel around can answer the set of questions and the system will provide tourist spot, path to the spot, some picture of the spot and rough estimated cost based on the answers given by the user. The primary advantage of this system is to fulfill user criteria by approximate estimation of cost and time.

Keywords: Aritificalintelligent, Travelling, If-then rule.

\section{INTRODUCTION}

The tourism industry has some specific features that explain its importance for many economic(regional) development and its inclination toward the IT system.

Many industries have a stronger hold on doing things traditionally, whereasthe travel and tourism industry has always been open to new technologies.

The tourism domain is an excellent example of the trend towards personalized services The tourists themselves will be one of the important contributors to the current context. Personalisation will also ensure that the suggestions are more relevant to the options given by the current user.

\section{IPROPOSED SYSTEM}

Users have to answer the set of questions and the system will provide tourist spot. Depending upon answer system also provide 1.path to the spot,2. Some picture of the spot ,3. Rough estimated cost to the user.Perform analysis on real-time Processing and use this to quantify the 'mood' of each point of interest..In the existing system the Systems have the information about the places they want to visit and they don't have usable or valuable information about points of interest except the phone numbers and addresses.

Example: MYMAP: Rule based recommendation, Weather\& Season considered. Textual representationof rationale for recommendation.

\section{RELATED WORK}

In 2013, Meehan .k et al[1] worked on the paper Context-Aware Intelligent Recommendation System for Tourism. The intelligent decision making that this paper proposes with regard to the development of the VISIT system, is a hybrid based recommendation approach made up of collaborative filtering, content based recommendation and demographic profiling. Intelligent reasoning will then be performed as part of this hybrid system to determine the weight/importance of each different context type.

In 2012, Lunney.T et al[2] worked on the paper Virtual Intelligent System for Informing Tourists -VISIT. Using additional context data can assist these applications in reducing information overload. However, it is important to include an appropriate level of personalization when performing content filtering to ensure the delivery of key focused information.

In 2012 Curran.k et al[3] worked on the paper A Social Media Based Tourist Information System. The benefit of this approach is integrating the social aspect of tourism between willing participants. This facilitates real-time interaction between tourists as they traverse their current environment. This will in turn lead to valuable synergistic information flows between tourists as they explore their surroundings and hence lead to a better, more informed and rewarding tourist experience. These information flows can also be valuable for the 
tourist information service when analyzing qualitative data regarding tourists visiting their city. Therefore, it is also imperative that mobile technology and social media are embraced by the tourism industry.

In 1991, Rob Lawson[4] worked on the paper Patterns Of Tourist Expenditure And Types Of Vacation Across The Family Life Cycle.This study examined the relationship between the family life cycle and tourist behavior, and found that stages in the family life cycle are reflected in both the type of vacation taken and financial expenditure made. Social orientation of young singles is evident, as are constraints imposed by children. Vacation activities correlate with the age of adult members of the group. Data are presented for accommodation, travel, meals, tours, shopping and entertainment, and reveal strong and consistent patterns of use for market segmentation.

In 2010, Haiyan.C [5] worked on the paper An impact of social media on online travel information search in China.Social media websites play more and more important role as information sources for travelers. The paper selects nine Chinese excellent tourism cities as sample with different city level, population size and geographic location, uses six main travel-related keywords to study empirically social media impact on online travel information search by Baidu search engine.

In 2002,Francesco Ricc et al[6] worked on the paper Travel recommended system. Recommender systems are commonly defined as applications that e-commercesites exploit to suggest products and provide consumers with information to facilitate their decision-making processes. 1 They implicitly assume that we can map userneeds and constraints, through appropriate recommendation algorithms, and convertthem into product selections using knowledge compiled into the intelligent recommender.

In 2014 ,Zhou F et al[7] worked on paper The Application of Intelligent Tourism Mobile Client Based On Ontology. This paper proposed the application of ontology theory in the research of intelligent tourism mobile application client. The adopted method (ontology) helps to structure the kind of information given to tourists thus eliminating room for information ambiguity. The strength of this research work is based on the fact that it makes use of an organic combination of the major elements that are closely linked to tourism, and infiltrates them it into every aspect of tourism which produces an effective, intelligent and efficient tourism information system. However, its weakness is based on the fact that it is mobile-based and hence accessibility is limited to mobile device users.

In 2016,American Scientific Research Journal for Engineering, Technology, and Sciences (ASRJETS.)[8]one system was designed for tourists taking Nigeria's tourism into consideration. This was to provide tourists with intelligent interaction based on virtual community concept of tourism and locals that have common interest theme. The system aims at bridging the gap; which is the lack of interaction that exists between tourists and locals at a particular destination. The system was designed using Java Applet (Net beans IDE 6.1), HTML, PHP and Java script whereas MySQL was used to design the database. The advantages of the system is it is user-friendly, interactive, supports security and compatible to various web servers but the system lacks intelligence in providing information to tourists, thus reducing the stress at which tourists seek for information on the system.

By Emest E et al[9] worked on the paper 'Intelligent Tourism Management System' . The system which tries to bridge the gap by noting what a tourist perceives as relevant, in terms of content pertaining to tourism products in tourism websites. This study focuses mainly on content because it is seen as the key factor associated with an effective website. Hence, the aim of this research entails the design and implementation of an intelligent platform that will assist tourists in gaining access to information on tourist locations in Nigeria.

\section{ARCHITECTURE DIAGRAM}

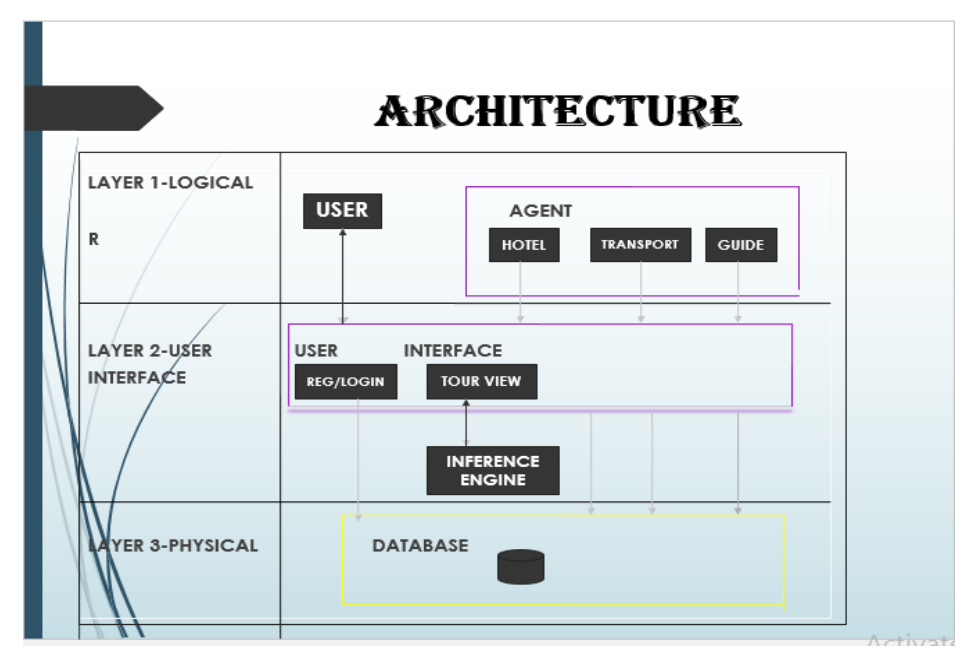




\section{CONCLUSION}

In this paper, we reviewed some of the methodologies based on online visiting and booking many different places auditing on Tourisum and also proposed the system to provide public auditing with user requirement depend on set of questions answered by user. We also have implemented easy payment system which does not support public auditing under secured manner. Since many groups of user have access the data about many places using the username and password. With advance research in this aspect, there can be advancement in our proposed system and can use better autendication.

\section{REFERENCES}

[1]. Meehan, K., Lunney, T., Curran, K., McCaughey, A. (2013) 'Context-Aware Intelligent Recommendation System for Tourism', In the Proceedings of the 11th IEEE International Conference on Pervasive Computing and Communications, San Diego, California.

[2]. Meehan, K., Lunney, T., Curran, K., McCaughey, A. (2012) 'VISIT: Virtual Intelligent System for Informing Tourists', In the Proceedings of the 13th Annual Post Graduate Symposium on the Convergence of Telecommunications, Networking and Broadcasting, Liverpool, England.

[3]. Meehan, K., Lunney, T., Curran, K., McCaughey, A. (2012) 'A Social Media Based Tourist Information System', In the Proceedings of the International Conference on Tourism and Events, Belfast, Northern Ireland.

[4]. Lawson, R. (1991) 'Patterns of tourist expenditure and types of vacation across the family life cycle', Journal of Travel Research , vol. 4, no. 29, April.

[5]. Haiyan, C. (2010) 'An impact of social media on online travel information search in China', International conference on Information management, Innovation management and Industrial engineering, Kunming, China, 509-512.

[6]. F. Ricci and H. Werthner, "Case-Based Querying for Travel Planning Recommendation," Information Technology and Tourism, vol. 4, nos. 3-4, 2002, pp. 215-226.

[7]. Zhou F, Zhao M, Sun Z, Zhao J \& Gong Z. (2014). The application of intelligence tourism mobile client based on ontology. Journal of Chemical and Pharmaceutical Research, Vol. 6(Isssue 5), pp 258-265.

[8]. Destination Information Management System for TouristsAmerican Scientific Research Journal for Engineering, Technology, and Sciences (ASRJETS) (2016) Volume 18, No 1, pp 304-315.

[9]. Ernest E. Onuiri,Henry C. Omoroje, Chukwudi G. Ntima, AyokunleA.Omotunde. Department of Computer Science, Babcock University, Ilishan-Remo, P.M.B 21244 Ikeja-Lagos OgunState, Nigeri,proposed paper 'intelligent Tourism Management System'. 